\title{
Brewer-Dobson Circulation: Recent-Past and Near-Future Trends Simulated by Chemistry-Climate Models
}

\author{
Dingzhu Hu, ${ }^{1}$ Yipeng Guo, ${ }^{2}$ Feiyang Wang, ${ }^{3}$ Qi Xu, ${ }^{1}$ Yuanpu Li, ${ }^{3}$ Wenjun Sang, ${ }^{3}$ \\ Xudong Wang, ${ }^{1}$ and Meichen Liu ${ }^{1}$ \\ ${ }^{1}$ Key Laboratory of Meteorological Disasters of China Ministry of Education (KLME), Joint International Research Laboratory of \\ Climate and Environment Change (ILCEC), Collaborative Innovation Center on Forecast and Evaluation of Meteorological Disasters \\ (CIC-FEMD), Nanjing University of Information Science \& Technology, Nanjing 210044, China \\ ${ }^{2}$ Key Laboratory of Mesoscale Severe Weather of Ministry of Education and School of Atmospheric Sciences, Nanjing University, \\ Nanjing 210093, China \\ ${ }^{3}$ Key Laboratory for Semi-Arid Climate Change of the Ministry of Education, College of Atmospheric Sciences, Lanzhou University, \\ Lanzhou 730000, China
}

Correspondence should be addressed to Yipeng Guo; guoyp@nju.edu.cn

Received 29 March 2017; Accepted 11 May 2017; Published 11 June 2017

Academic Editor: Yu Liu

Copyright (C) 2017 Dingzhu Hu et al. This is an open access article distributed under the Creative Commons Attribution License, which permits unrestricted use, distribution, and reproduction in any medium, provided the original work is properly cited.

\begin{abstract}
Based on data from 16 chemistry-climate models (CCMs) and separate experimental results using a state-of-the-art CCM, the trends in the Brewer-Dobson circulation (BDC) during the second half of the 20th century (1960-2000) and the first half of the 21st century (2001-2050) are examined. From the ensemble mean of the CCMs, the BDC exhibits strengthening trends in both the 20th and 21st centuries; however, the acceleration rates of tropical upwelling and southern downwelling during 2001-2050 are smaller than those during 1960-2000, while the acceleration rate of the northern downward branch of the BDC during 2001-2050 is slightly larger than that during 1960-2000. The differences in the extratropical downwelling trends between the two periods are closely related to changes in planetary-wave propagation into the stratosphere caused by the combined effects of increases in the concentrations of greenhouse gases (GHGs) and changes in stratospheric ozone. Model simulations demonstrate that the response of southern downwelling to stratospheric ozone depletion is larger than that to the increase in GHGs, but that the latter plays a more important role in the strengthening of northern downwelling. This result suggests that, under the expected future climate, northern downwelling will play a more important role in balancing tropical upwelling.
\end{abstract}

\section{Introduction}

The Brewer-Dobson circulation (BDC) consists of an upward transport branch across the tropical tropopause in the tropics and downward and poleward transport branches in the extratropics in the two hemispheres [1]. Changes in the BDC can modulate the global radiation balance by affecting the meridional distribution of the natural and anthropogenic tracer gases in the stratosphere, further influencing climate and environmental changes at the global scale [2-7]. For example, ozone-depleting substances that follow the BDC are transported into the polar stratosphere where they influence the concentration of ozone [8-12]. As the meridional distribution of trace gases in the stratosphere is closely related to the $\mathrm{BDC}[2,10,13]$, changes in the BDC are important to the formation and recovery of the stratospheric ozone hole.

Because of the important implications of the nature of the BDC to the climate of the troposphere and stratosphere, it is a phenomenon that has attracted an increasing amount of attention in the scientific community [14-16]. Early studies showed that an increase in the concentrations of greenhouse gases (GHGs) causes a stronger BDC [17]. Subsequently, observational and modelling studies further confirmed that a doubling of the $\mathrm{CO}_{2}$ concentration results in a strengthened BDC [2, 3, 18-20]. However, Engel et al. [21] reported that the mean age of air during the past three decades exhibits a slightly increasing trend, implying that the BDC has been marginally weakened during the past three decades. But their 
TABLE 1: CCMVal-2 models used in this study ${ }^{\mathrm{a}}$.

\begin{tabular}{|c|c|c|c|c|c|}
\hline Model name & Resolution & Vertical layers & Model top & $\begin{array}{c}\text { REF-B1 } \\
(1960-2000)\end{array}$ & $\begin{array}{c}\text { REF-B2 } \\
(2001-2050) \\
\end{array}$ \\
\hline AMTRAC3 & $2^{\circ} \times 2.5^{\circ}$ & 48 & $0.0017 \mathrm{hPa}$ & 1 & \\
\hline CAM3.5 & $2^{\circ} \times 2^{\circ}$ & 31 & $0.10 \mathrm{hPa}$ & 1 & 1 \\
\hline CCSRNIES & $2.8^{\circ} \times 2.8^{\circ}$ & 34 & $0.01 \mathrm{hPa}$ & 1 & 1 \\
\hline CMAM & $3.75^{\circ} \times 3.75^{\circ}$ & 71 & $0.0006 \mathrm{hPa}$ & 3 & 3 \\
\hline CNRM-ACM & $1.9^{\circ} \times 1.9^{\circ}$ & 31 & $0.10 \mathrm{hPa}$ & 2 & 1 \\
\hline E39CA & $3.75^{\circ} \times 3.75^{\circ}$ & 39 & $10 \mathrm{hPa}$ & 1 & \\
\hline EMAC & $2.8^{\circ} \times 2.8^{\circ}$ & 31 & $0.10 \mathrm{hPa}$ & 1 & \\
\hline GEOSCCM & $2^{\circ} \times 2.5^{\circ}$ & 55 & $0.01 \mathrm{hPa}$ & 1 & 1 \\
\hline LMDZrepro & $2.5^{\circ} \times 3.75^{\circ}$ & 50 & $0.07 \mathrm{hPa}$ & 3 & \\
\hline MRI & $2.8^{\circ} \times 2.8^{\circ}$ & 68 & $0.01 \mathrm{hPa}$ & 4 & 2 \\
\hline Niwa-SOCOL & $3.75^{\circ} \times 3.75^{\circ}$ & 31 & $0.1 \mathrm{hPa}$ & 1 & \\
\hline SOCOL & $3.75^{\circ} \times 3.75^{\circ}$ & 39 & $0.1 \mathrm{hPa}$ & 3 & 3 \\
\hline ULAQ & $10^{\circ} \times 22.5^{\circ}$ & 26 & $0.04 \mathrm{hPa}$ & 1 & \\
\hline UMSLIMCAT & $2.5^{\circ} \times 3.75^{\circ}$ & 64 & $0.01 \mathrm{hPa}$ & 1 & 1 \\
\hline UMUKCA-METO & $2.5^{\circ} \times 2.5^{\circ}$ & 31 & $10 \mathrm{hPa}$ & 1 & 1 \\
\hline WACCM & $4^{\circ} \times 5^{\circ}$ & 66 & $4.5 \times 10^{-6} \mathrm{hPa}$ & 4 & 3 \\
\hline
\end{tabular}

${ }^{\mathrm{a}}$ The numbers in the fourth and fifth columns represent the number of ensemble members; more details are available in Morgenstern et al. [28].

result has been subsequently debated in the literature [22, 23]. Garcia et al. [23] showed that there are large errors in the observed mean age-of-air trend and that the trend is negative in numerical models, which is consistent with the acceleration of the BDC under the increase in GHGs [2, 3, 18-20]. Subsequently, Wang et al. [24] showed a weakening trend of the BDC during 1979-2011, based on ERA-Interim data. Therefore, the strength of the BDC in recent decades remains under debate.

Since the BDC has important impacts on the climate of the troposphere and stratosphere [2-6], it is also important to be able to predict its trend under the expected climatic conditions of the future. As mentioned above, an increase in the concentration of $\mathrm{CO}_{2}$ results in an accelerated $\mathrm{BDC}$ $[2,3,18-20]$, and stratospheric ozone depletion can also lead to a strengthening of downwelling in the high-latitude stratosphere $[2,25]$. However, following the decline in stratospheric ozone from the late 1970s to late 1990s, its trend in the 21st century is expected to be a rising one [8], possibly even recovering to pre-1980 levels by around $2050[26,27]$. Xie et al. [2] showed that an increase in stratospheric ozone results in a decrease in the tropical mass flux across the tropopause and, recently, $\mathrm{Hu}$ et al. [10] found that the potential ozone recovery under the expected future climate will result in a weaker $\mathrm{BDC}$ during boreal winter. It is apparent, therefore, that the influences on the BDC of increased GHGs and stratospheric ozone recovery are opposite. As such, the nature of the BDC under the expected characteristics and trends of these two factors in the future remains an open question in need of further investigation.

Because of the lack of high spatial and temporal resolution datasets, numerical models, which can simulate stratospheric processes well, are currently the best tools available for investigating and predicting the long-term changes in the BDC. More specifically, chemistry-climate models (CCMs), which consider radiational, chemical, and dynamical processes, have been developed well in recent years [28, 29]. In the present study, outputs from 16 CCMs are used to analyze the BDC trends in the second half of the 20th century (1960-2000) and the first half of the 21st century (2001-2050). Furthermore, a series of time-slice simulations using a stateof-the-art CCM are designed to investigate the relative impacts of GHGs and stratospheric ozone changes on the BDC.

The remainder of this paper is organized as follows: Section 2 describes the CCM data, method, and the design of the numerical experiments; Section 3 analyzes the BDC trends in the recent-past (1960-2000) and in the near-future (2001-2050); Section 4 examines the planetary-wave flux trends of the two periods; Section 5 discusses the effects of GHGs and stratospheric ozone changes on the BDC; and Section 6 summarizes the study and our conclusions.

\section{Data, Method, and Numerical Simulations}

2.1. Data. The datasets used in this study are the outputs from $16 \mathrm{CCM}$ evaluated during the chemistry-climate model validation activity, round 2-part of the StratosphereTroposphere Processes and Their Role in Climate Project (http://www.sparc-climate.org/). Basic details of the CCMs are provided in Table 1 , but more information on these models and their simulations can be found in Eyring et al. [29] and Morgenstern et al. [28].

2.2. Method. Changes in the BDC can be quantified by the changes in the tropical upward mass flux and extratropical 
TABLE 2: Configurations of the ozone, GHGs, and SST fields adopted in the experiments.

\begin{tabular}{lccc}
\hline Experiments & Ozone & GHGs & SST \\
\hline REF & $1979-1983$ & 1980 & $1975-1984$ \\
OZONE2000 & $1998-2002$ & Same as REF & Same as REF \\
GHG2000 & Same as REF & 2020 & $1995-2004$ \\
\hline
\end{tabular}

downward mass fluxes [30]. The upward and downward mass fluxes associated with the BDC are represented in terms of the mass stream function, $F_{m}[31]$ :

$$
\begin{aligned}
& F_{m}=\frac{2 \pi a \psi}{g} \\
& \frac{\partial \psi}{\partial \phi}=-a \cos \phi \overline{\omega^{*}}, \\
& \frac{\partial \psi}{\partial p}=\cos \phi \overline{v^{*}} .
\end{aligned}
$$

Here, $\psi$ is the residual stream function given by (2); $v^{*}$ and $\omega^{*}$ are the meridional and vertical velocities of the BDC, respectively, defined in Edmon et al. [32]; $a$ is radius of the Earth; and $g$ is Earth's gravitational acceleration. The tropical upward mass flux at a given level is determined by integrating (1) between the turnaround latitudes, which are the latitudes near the tropics where the circulation is upwards. The downward mass fluxes in the two hemispheres are integrated poleward from the turnaround latitudes in both hemispheres.

2.3. Model and Simulations. We also design and run three time-slice simulations in the Whole Atmosphere Community Climate Model, version 3 (WACCM3). This CCM has 66 vertical levels from the ground to an altitude of approximately $150 \mathrm{~km}$ and performs well in simulating stratospheric processes $[29,33]$. More details on WACCM3 can be found in Garcia et al. [34]. The three time-slice simulations are performed at a horizontal resolution of $1.9^{\circ} \times 2.5^{\circ}$ (latitude $\times$ longitude) with interactive chemistry processes switched off. All simulations are run for 56 years, with the first 4 years used as spin-up.

The configurations of ozone, GHGs, and sea surface temperature (SST) fields adopted in the three experimentsnamed REF, OZONE2000, and GHG2000-are listed in Table 2. The GHGs values in all simulations are taken from the Intergovernmental Panel on Climate Change AR4 B1 scenarios [35]. The monthly mean SST and sea-ice climatologies for the periods 1975-1984 and 1995-2004 are from the Hadley Centre. The ozone forcings used in this study are two monthly-varying zonal mean climatologies, taken from the WACCM reference simulation performed for CCMVal-2 [33]. Differences between the runs of GHG2000 and REF, as well as those between OZONE2000 and REF, are used to investigate the impacts of GHGs increases and stratospheric ozone depletion on the BDC.

\section{BDC Trends in the CCMs}

Figure 1 shows that the vertical velocity of tropical upwelling has a rising trend in the historical period (1960-2000) throughout the entire stratosphere, and this is accompanied by a rising trend in the vertical velocity of extratropical downwelling (Figure 1(a)). The strengthening trend of $w^{*}$ in the Southern Hemisphere ( $\mathrm{SH}$ ) is larger than that in the Northern Hemisphere $(\mathrm{NH})$ during that same period. By contrast, during 2001-2050, while the tropical upward vertical velocity still rises, the rapidity of the increase is smaller than that during 1960-2000. Meanwhile, the northern downwelling still shows a strengthening trend during the future period (2001-2050), but with a slightly larger magnitude compared to the historical period (1960-2000). Note that the Antarctic downwelling has a statistically significant weakened trend over the period 2001-2050 (Figure 1(a)), which is different to the strengthened trend over the period 1960-2000 (Figure 1(b)). This indicates that the $\mathrm{BDC}$ branch in the Antarctic stratosphere will be weakened in the future, while the BDC branch in the southern mid-latitudes will be strengthened.

To quantify the trends in the BDC under the conditions of past and future climate, we examine the vertical profiles of the trends in the annual mean tropical upward mass flux and northern and southern downward mass fluxes during the two periods (Figure 2). As can be seen, the tropical upward mass flux increases by $0.12 \times 10^{9} \mathrm{~kg} \mathrm{~s}^{-1} / 10 \mathrm{yr}$ at $10 \mathrm{hPa}$ during 1960-2000 (Figure 2(a)), which is about twice the trend of tropical upward mass flux during 2001-2050. This is consistent with the results in Figure 1. The southern and northern downward mass fluxes during the historical and future periods both have rising trends. More specifically, compared to $1960-2000$, the southern downward mass flux during 2001-2050 has a rising trend but with a slower rate of change (Figure 2(b)), whereas the northern downward mass flux has a rising trend with a faster rate of change (Figure 2(c)). Note also that the northern downwelling in the upper stratosphere (lower stratosphere) during 2001-2050 exhibits a smaller (larger) rising trend compared to that during 1960-2000. This is possibly related to the stratospheric ozone recovery of this period, which has been shown to weaken the northern downwelling in the middle-to-upper stratosphere [36] because of the decreased planetary-wave amplitude in the lower stratosphere in response to such a recovery. By comparing Figures 2(a), 2(b), and 2(c), it is apparent that the tropical upward mass flux is mainly balanced by the southern downward mass flux during the historical period, whereas during the future period the tropical upwelling is mainly balanced by the northern downward mass flux. This suggests a greater importance of the northern downward mass flux in the past because in the future there may be more mass flux transported from the stratosphere into the troposphere through the tropopause at northern mid- and highlatitudes than at southern mid- and high-latitudes, which may further affect the atmospheric mass in the troposphere [37-39].

To better understand the difference in the southern and northern downwelling trends between the historical and future periods and considering the seasonal dependence of 


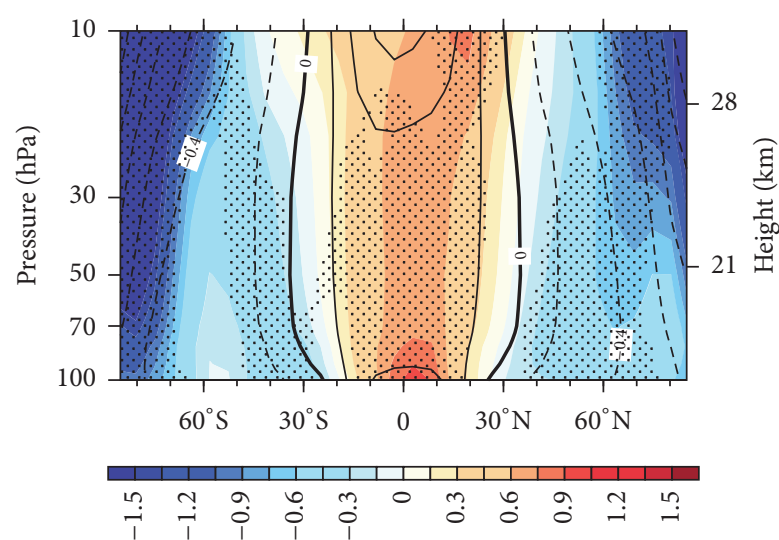

(a) $w^{*}[1960-2000]$

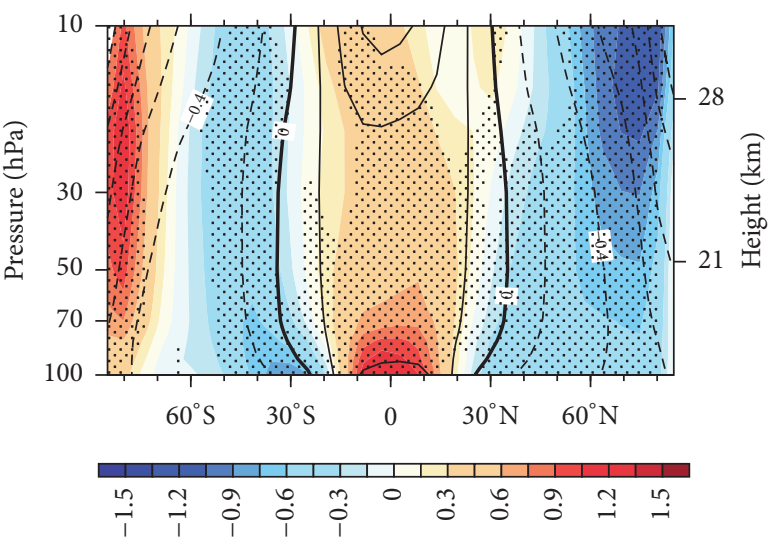

(b) $w^{*}[2001-2050]$

FIGURE 1: Trends (color fill; units: $10^{-2} \mathrm{~mm} \mathrm{~s}^{-1}$ decade ${ }^{-1}$ ) and climatologies (contours; units: $10^{-3} \mathrm{~mm} \mathrm{~s}^{-1}$ ) of annual mean $w^{*}$ derived from the CCMs' ensemble mean over the periods (a) 1960-2000 and (b) 2001-2050. The contour interval for the climatological $w^{*}$ is $0.2 \times 10^{-3} \mathrm{~mm} \mathrm{~s}^{-1}$. Solid and dashed lines represent positive and negative contours, respectively. Stippled regions show the trends significant at the $90 \%$ level.

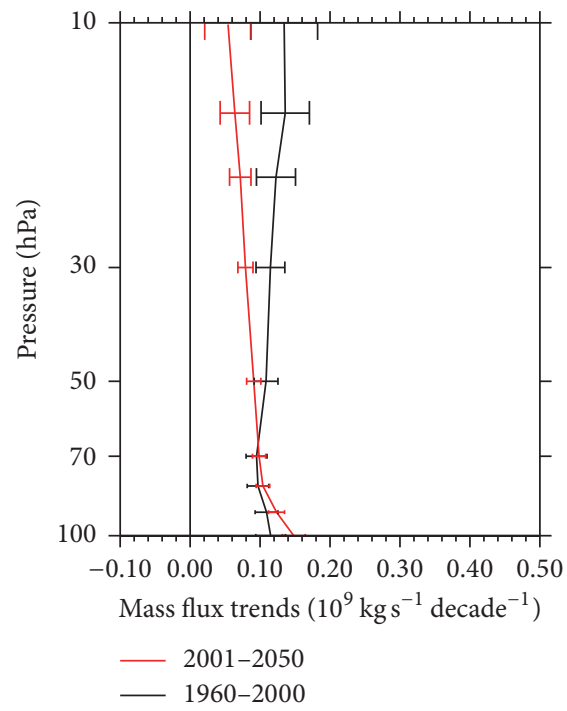

(a) Tropical upwelling

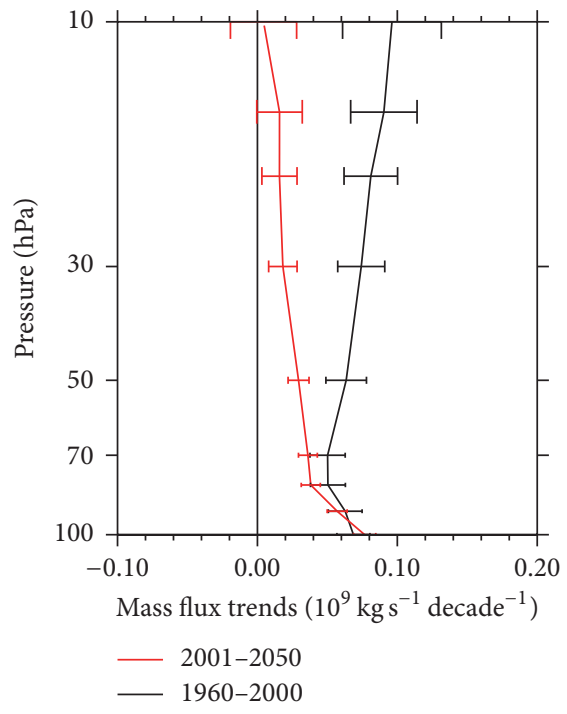

(b) SH downwelling

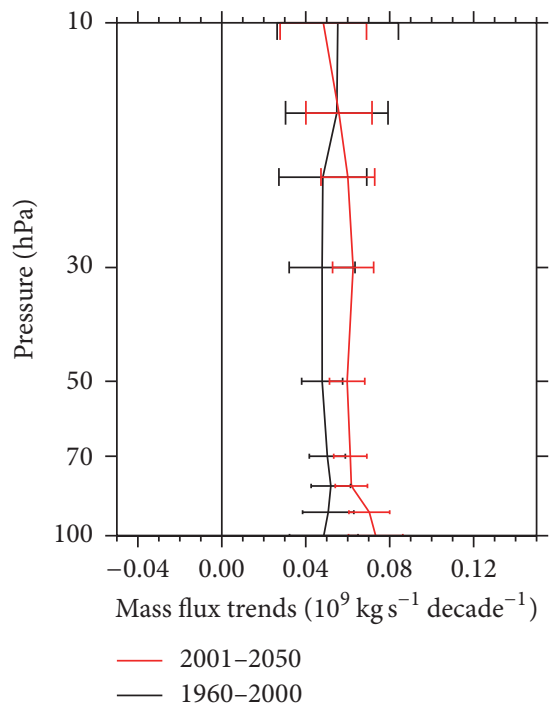

(c) NH downwelling

FIGURE 2: Vertical profiles of the trends in annual mean (a) tropical upward mass flux, (b) downward mass flux in the $\mathrm{SH}$, and (c) downward mass flux in the NH, over the periods 1960-2000 (black lines) and 2001-2050 (red lines), derived from the ensemble mean of the CCMVal-2 models. The error bars represent the $95 \%$ confidence level.

the BDC branches [40], we analyze the seasonal climatologies and trends of $w^{*}$ during the two periods (Figures 3 and 4). The climatologies of the tropical $w^{*}$ in the lower and middle stratosphere are largest in June-August (JJA) and December-February (DJF), with the largest southern downwelling in JJA and the largest northern downwelling in DJF, which is closely related to the strongest wave activity in the southern stratosphere during JJA and in the northern stratosphere during DJF [40]. Furthermore, the largest strengthening trend of the southern downwelling during 1960-2000 is in DJF, while the southern downwelling during 2001-2050 in DJF has a statistically significant weakening trend. The largest strengthening trend in the northern downwelling over the two periods is in both cases in DJF. By comparing Figures 1, 3, and 4 , it is apparent that changes in extratropical downwelling in both hemispheres in DJF play important roles in the trend of annual mean BDC branches in the two hemispheres.

From the annual and seasonal trends of mass flux at $70 \mathrm{hPa}$ in the CCMs' ensemble mean during the historical and future periods (Figure 5), we can also see that the trends of the tropical upwelling and southern and northern downwelling trends during 1960-2000 are largest in DJF. The smaller (larger) acceleration of the annual mean southern (northern) downwelling during 2001-2050 than that during 1960-2000 is mainly contributed by that in DJF; therefore, we focus on the DJF trends of planetary-wave flux in the following section. Note that the smaller acceleration rate of the tropical upwelling in DJF during 2001-2050 than that during 


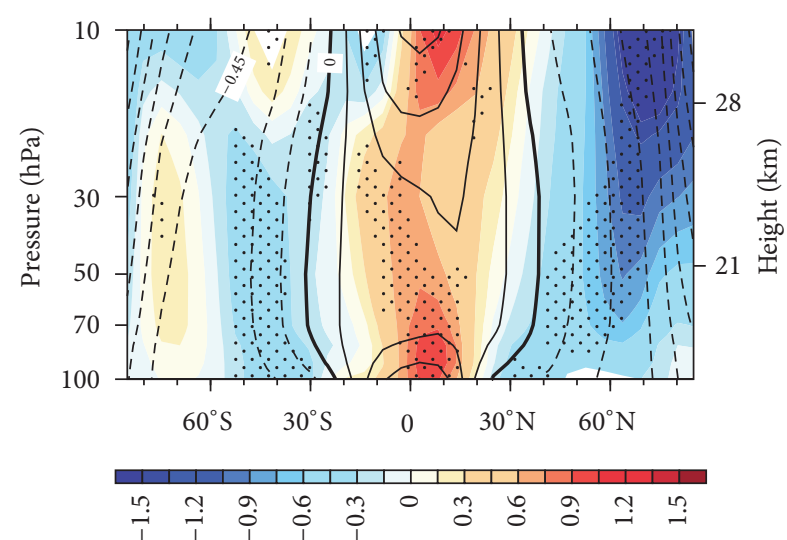

(a) MAM [1960-2000]

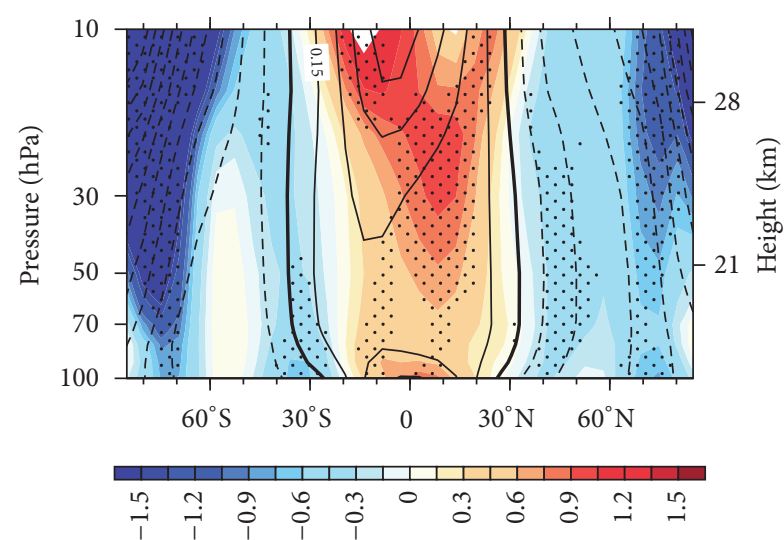

(c) SON [1960-2000]

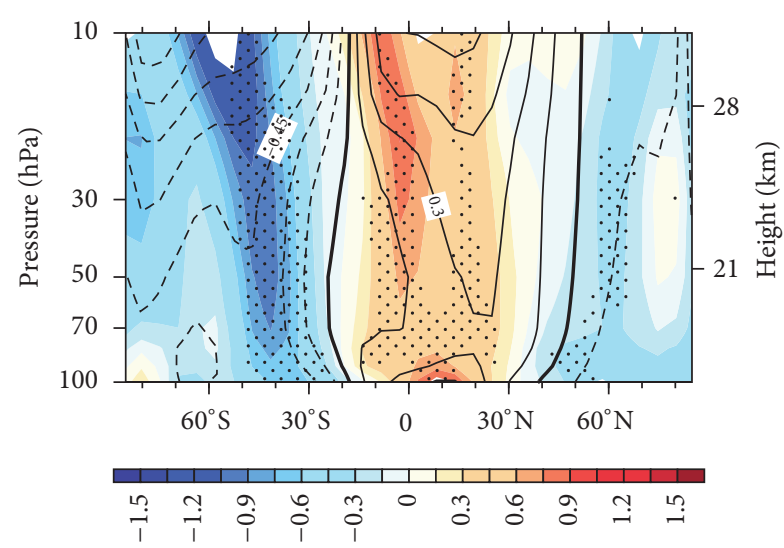

(b) JJA [1960-2000]

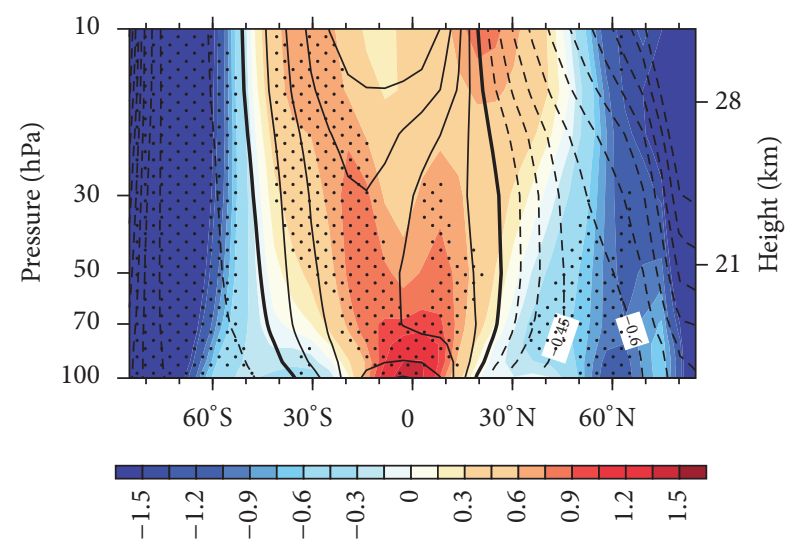

(d) DJF [1960-2000]

FIgure 3: Trends (color fill; units: $10^{-2} \mathrm{~mm} \mathrm{~s}^{-1}$ decade $^{-1}$ ) and climatologies (contours; units: $10^{-3} \mathrm{~mm} \mathrm{~s}^{-1}$ ) in the $w^{*}$ derived from the CCMs' ensemble mean averaged over (a) March-April-May (MAM), (b) June-July-August (JJA), (c) September-October-November (SON), and (d) December-January-February (DJF), over the period 1960-2000. The contour interval for the climatological $w^{*}$ is $0.2 \times 10^{-3} \mathrm{~mm} \mathrm{~s}^{-1}$. Solid and dashed lines represent positive and negative contours, respectively. Stippled regions show the trends significant at the $90 \%$ level.

1960-2000 (Figure 5(a)) is mainly balanced by the smaller acceleration rate of the southern downwelling (Figure 5(b)), which is consistent with the results in a previous study [40].

\section{Planetary-Wave Flux Trends}

A question arises as to why the southern and northern downwelling trends are different between the two periods. As BDC changes are closely related to the wave activity in the stratosphere, to better understand such changes in the $\mathrm{BDC}$, it is necessary to examine the trends in stratospheric wave activity. Before we discuss the wave-flux trends in the stratosphere, we start by examining the trends in temperature and zonal wind during the historical and future periods in DJF (Figure 6). As we can see from Figure 6(a), the troposphere gets warmer and the stratosphere gets colder during 1960-2000 (Figure 6(a)), with the largest cooling trend in the stratosphere being in the Antarctic lower stratosphere, mainly because it is the region with the largest depletion of stratospheric ozone $[10,40]$. Note also that the temperature in the Antarctic middle stratosphere during 1960-2000 exhibits a rising trend, which is in accordance with the region's rising trend of the stratospheric ozone during austral summer there $[10,40]$.

Compared to the results during 1960-2000, the rising trend of tropospheric temperature during 2001-2050 is larger and extends higher into the lower stratosphere; plus, at surface level in the northern high-latitudes, the trend is statistically significant (Figure 6(c)). The largest difference in stratospheric temperature between the two periods is in the Antarctic lower stratosphere. The cooled Antarctic lower stratosphere during 1960-2000 reverses to a warmed one during 2001-2050, mainly due to the recovery of Antarctic ozone during the 21 st century [10, 40, 41]. Interestingly, the temperature of the Arctic lower stratosphere also reverses from the historical to the future period-from a declining trend in the former to a rising trend in the latter (Figure 6(c)) - which is consistent with the results reported by $\mathrm{Hu}$ et al. [41].

Through the thermal wind balance relationship, changes in temperature structure can affect the latitudinal temperature gradients and further alter the structure of zonal winds. Consistent with the results in $\mathrm{Li}$ et al. [40], the strengthened westerly wind in the Antarctic stratosphere during 1960-2000 


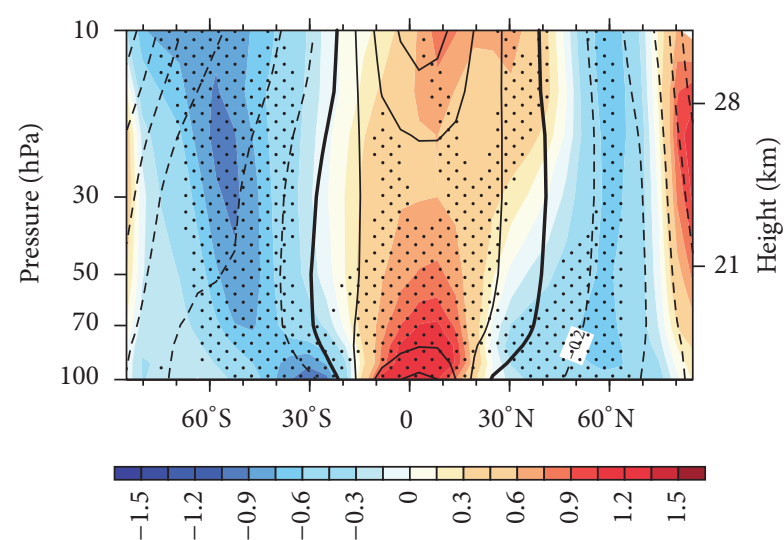

(a) MAM [2001-2050]

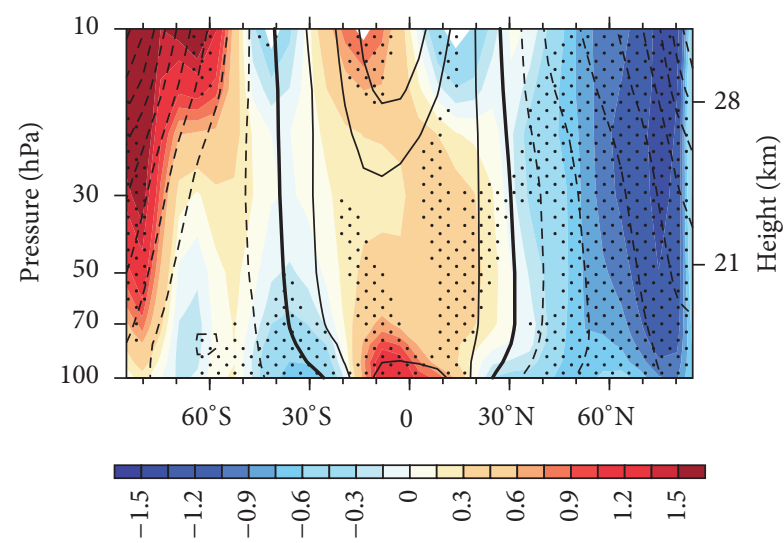

(c) SON [2001-2050]

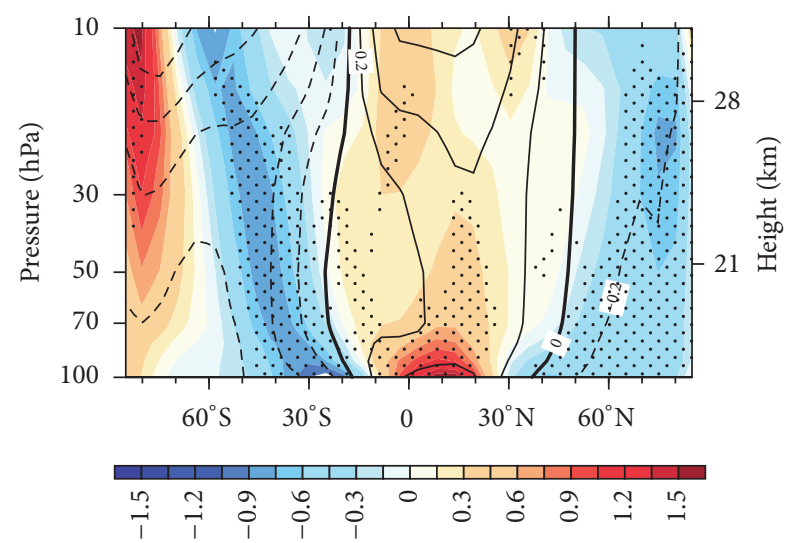

(b) JJA [2001-2050]

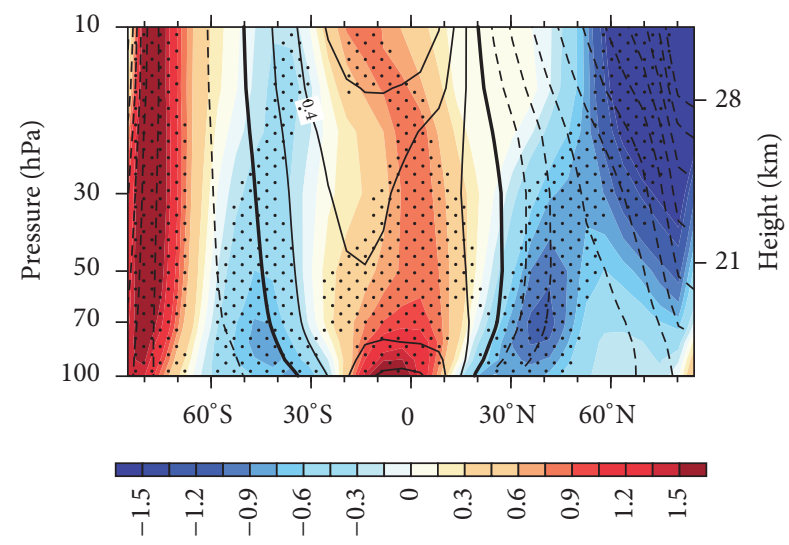

(d) DJF [2001-2050]

FIGURE 4: As in Figure 3, but for the period 2001-2050.

can be seen clearly in Figure 6(b). We can also see that the southern subtropical jet during 1960-2000 displaces poleward, which is in accordance with the results reported by Son et al. [42]. During 2001-2050, the warmed Antarctic stratosphere may lead to a weakened latitudinal temperature gradient (Figure 6(c)), which, following the thermal wind relationship, would be accompanied by a weakened westerly wind in the Antarctic stratosphere and an equatorward displacement of the southern subtropical jet (Figure 6(d)).

The above-mentioned zonal wind changes imply a change in refractive index [10], which in turn can influence the propagation of planetary waves from the troposphere to the stratosphere $[5,43]$. As the eddy heat flux $\left(\overline{v^{\prime} T^{\prime}}\right)$ can well represent the vertical flux of wave activity well [44], we examine the trends of eddy heat flux in DJF during the two periods (Figure 7). The wave flux over the Antarctic stratosphere exhibits a significantly enhanced trend during 1960-2000 (Figure 7(a)) and a weakened trend during 2001-2050 (Figure 7(c)), which is in accordance with the region's temperature and zonal wind (Figure 6). Stronger (weaker) planetary-wave flux in the Antarctic stratosphere during 1960-2000 (2001-2050) is in accordance with the strengthening (weakening) of the upper flanks of subtropical jets during the two periods (Figure 6).
Shepherd and McLandress [43] reported that a strengthening of the upper flanks of the subtropical jet is conducive to more waves penetrating the subtropical lower stratosphere. It should, however, be noted that the eddy heat flux trend over the Arctic stratosphere is a declining one, but not statistically significant. Meanwhile, the eddy heat flux over the mid-latitude stratosphere shows a rising trend in the two periods (Figures $7(\mathrm{~b})$ and $7(\mathrm{~d})$ ), and the strengthening trend in the eddy heat flux at northern mid-latitudes in the lower stratosphere during 2001-2050 is statistically significant (Figure $7(\mathrm{~d})$ ), which is possibly the reason why the acceleration of the northern downward branch of the BDC over 2001-2050 is slightly larger than that over 1960-2000.

\section{Effects of GHGs and the Stratospheric Ozone on the BDC}

Previous studies have shown that an increase in GHGs leads to a warmer troposphere and a cooler stratosphere via its direct radiational effects and indirect SST effects, which in turn affects the wave propagation from the troposphere into the stratosphere and further strengthens the BDC [5]. Stratospheric ozone has important impacts on the BDC 


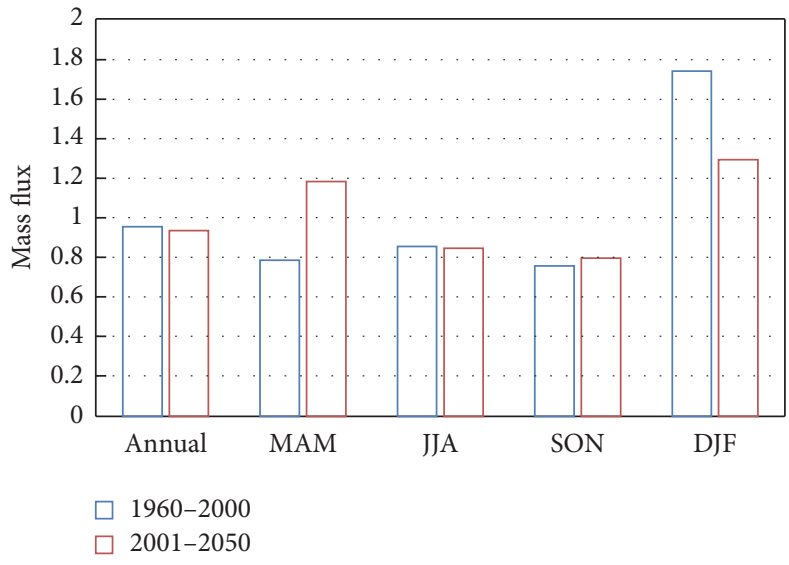

(a) Tropical upwelling

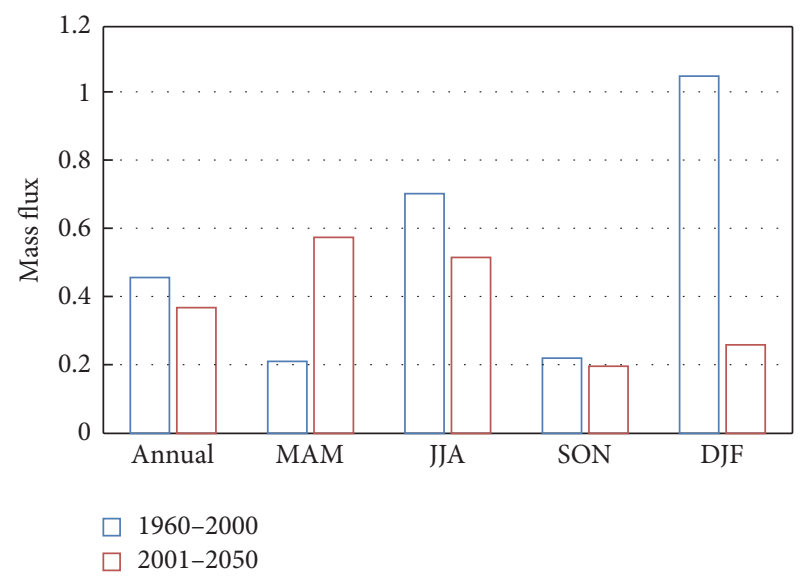

(b) SH downwelling

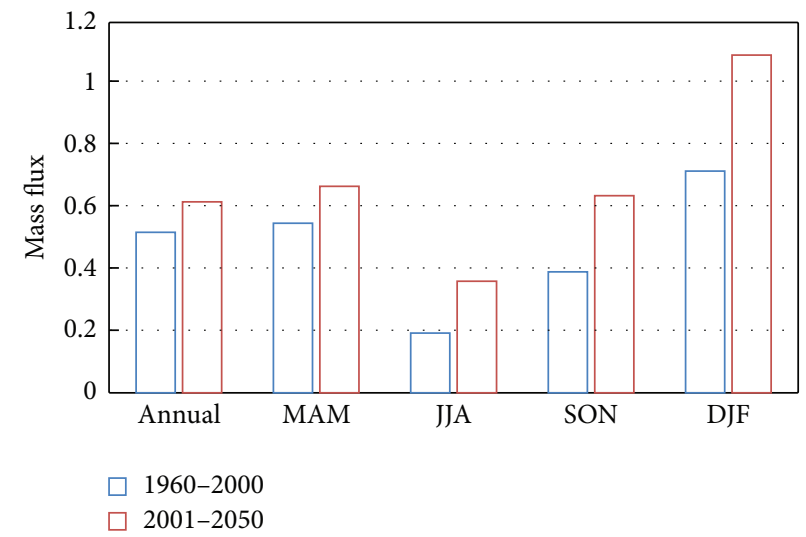

(c) NH downwelling

Figure 5: Annual and seasonal mean mass flux trends (units: $10^{9} \mathrm{~kg} \mathrm{~s}^{-1}$ decade $^{-1}$ ) at $70 \mathrm{hPa}$ from the CCMs' ensemble mean during $1960-2000$ (blue boxes) and 2001-2050 (red boxes): (a) tropical upwelling; (b) SH downwelling; (c) NH downwelling.

through the radiational and chemical processes $[2,45,46]$. Oman et al. [45] showed that stratospheric ozone depletion tends to weaken the BDC. Thus, the question arises as to what effects on the BDC take place as a result of increased concentrations of GHGs and changes in stratospheric ozone depletion.

To investigate the separated effects of GHGs and stratospheric ozone on stratosphere-troposphere exchange, we design and run three numerical simulations in WACCM3 (see Section 2.3). The responses of the BDC to the increased GHGs and stratospheric ozone depletion (Figure 8) show that, as expected, the tropical upward mass flux-in response to both factors-increases (Figure 8(a)), and this is accompanied by increased southern downward mass flux (Figure 8(b)) and northern downward mass flux (Figure 8(c)). Note also that the magnitude of the increase in tropical upward mass flux in response to elevated GHGs is larger than that in response to stratospheric ozone depletion (Figure 8(a)). However, the magnitude of the increase in southern downward mass flux caused by the increase in GHGs is much smaller than that caused by the stratospheric ozone depletion (Figure $8(\mathrm{~b})$ ), while the response of the northern downward mass flux to elevated GHGs is stronger than that to stratospheric ozone depletion (Figure 8(c)). That is, the strengthening of the southern downward mass flux in response to stratospheric ozone depletion overwhelms that in response to the increase in GHGs, but the response of the northern downward mass flux to stratospheric ozone depletion is less significant than that to GHGs.

The net tropical upward and extratropical downward mass flux at $72 \mathrm{hPa}$ associated with the BDC in different experiments are listed in Table 3. The stratospheric ozone depletion causes a $2.6 \%$ increase in the tropical upward mass flux, while the rise in GHGs causes a larger increase (by $4.1 \%)$, which is consistent with previous results $[2,3,10]$. Note also that the southern mid-high-latitude downward mass flux caused by the stratospheric ozone depletion increases by $16.0 \%$, which is much larger than the $5.5 \%$ increase caused by the rise in GHGs. However, the northern mid-high-latitude downward mass flux caused by the increase in GHGs is larger than that caused by stratospheric ozone depletion; for instance, the downward mass flux in the $\mathrm{NH}$ caused by the rise in GHGs and by stratospheric ozone depletion increases by $3.9 \%$ and $-0.4 \%$, respectively. These results are consistent with the results shown in Figure 8, further confirming that the increase in GHGs has a greater effect 


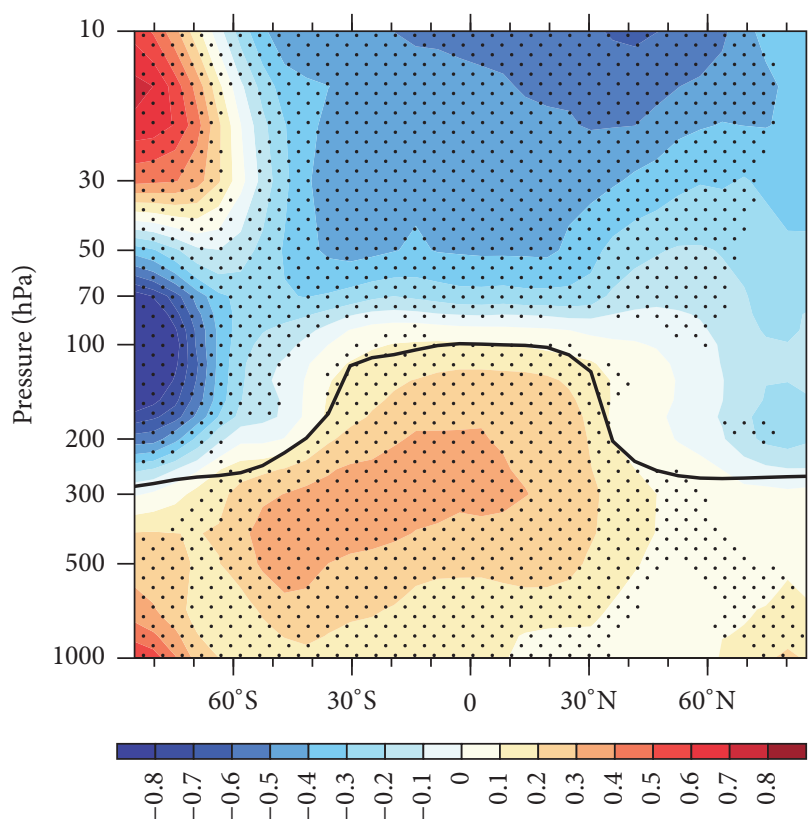

(a) $T$ [1960-2000]

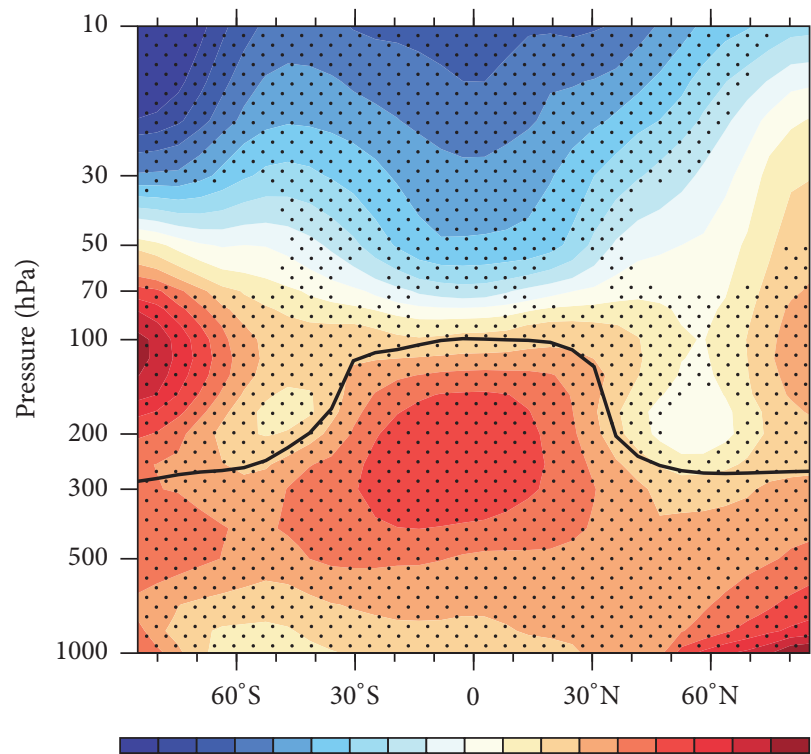

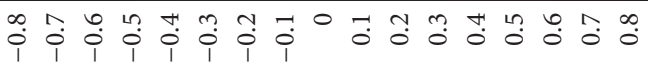

(c) $T$ [2001-2050]

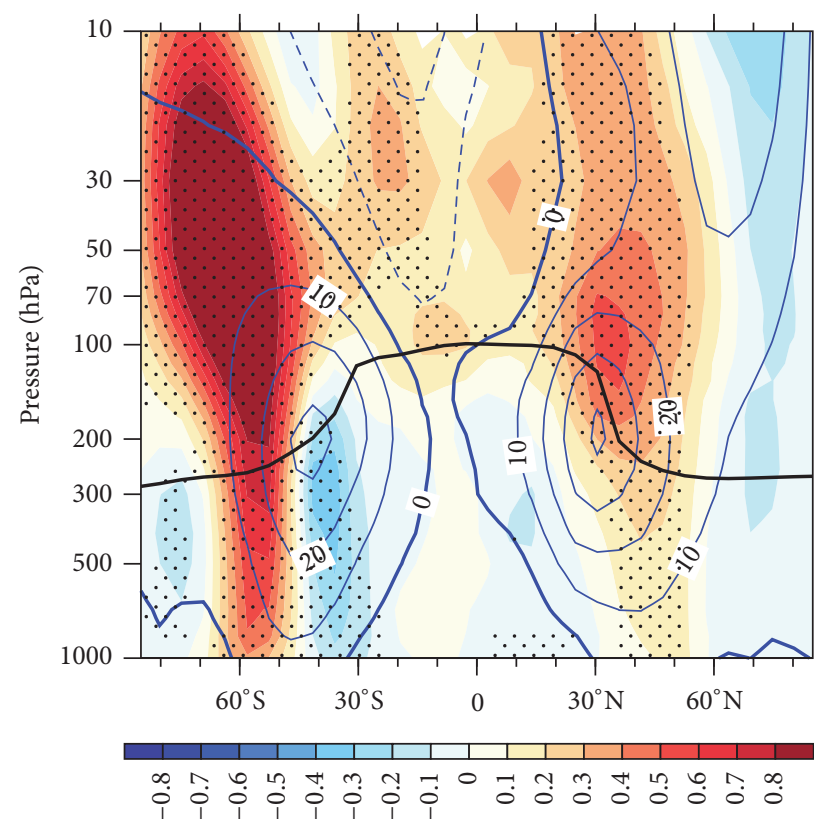

(b) $U$ [1960-2000]

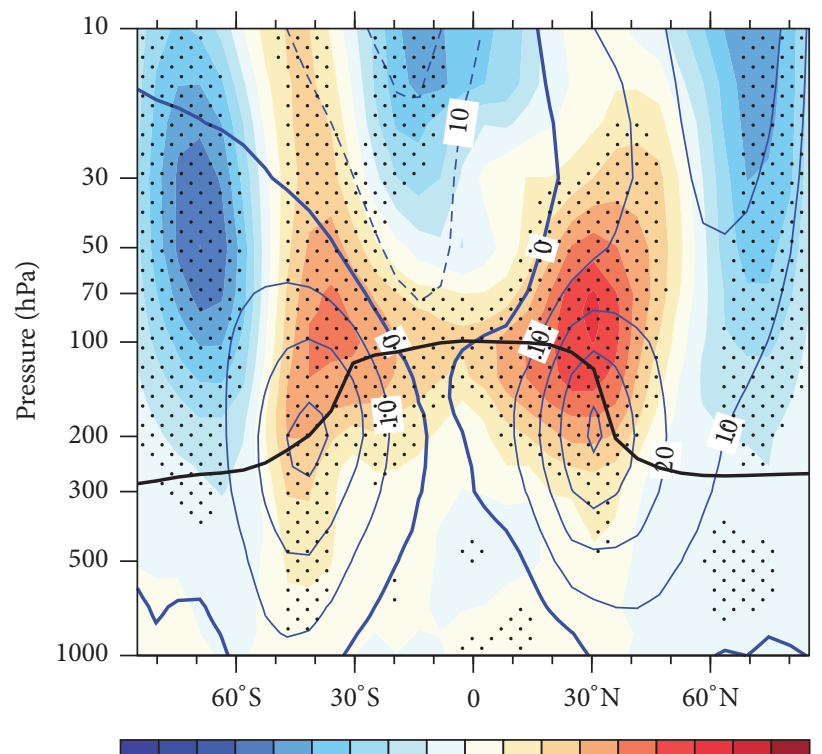

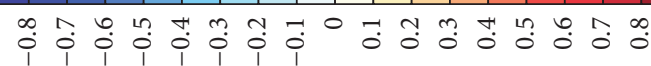

(d) $U[2001-2050]$

FIGURE 6: Trends in temperature ((a) and (c) units: $\mathrm{K} \mathrm{decade}^{-1}$ ) and zonal wind ((b) and (d) color fill; units: $\mathrm{m} \mathrm{s}^{-1}$ decade $^{-1}$ ) derived from the CCMs' ensemble mean in DJF over the periods ((a)-(b)) 1960-2000 and ((c)-(d)) 2001-2050. The contour interval for the climatological zonal wind is $10 \mathrm{~m} \mathrm{~s}^{-1}$. Solid and dashed blue lines represent positive and negative contours of climatological zonal winds, respectively. The thick black lines represent the climatological positions of the thermal tropopause. Stippled regions show the trends significant at the $95 \%$ level.

on the tropical upwelling and northern downwelling while stratospheric ozone depletion has a greater effect on the southern downwelling.

The responses of zonal mean temperature and zonal winds in DJF to stratospheric ozone depletion and elevated GHGs (Figure 9) demonstrate that stratospheric ozone depletion has no significant effects on tropospheric temperature
(Figure 9(a)) and that tropospheric warming is mainly caused by the increase in GHGs (Figure 9(c)), consistent with the results of Xie et al. [2]. However, the cooling of the Antarctic stratosphere caused by stratospheric ozone depletion (Figure 9(a)) is much larger than that caused by the increase in GHGs (Figure 9(c)), which in turn results in a larger temperature gradient in response to stratospheric 


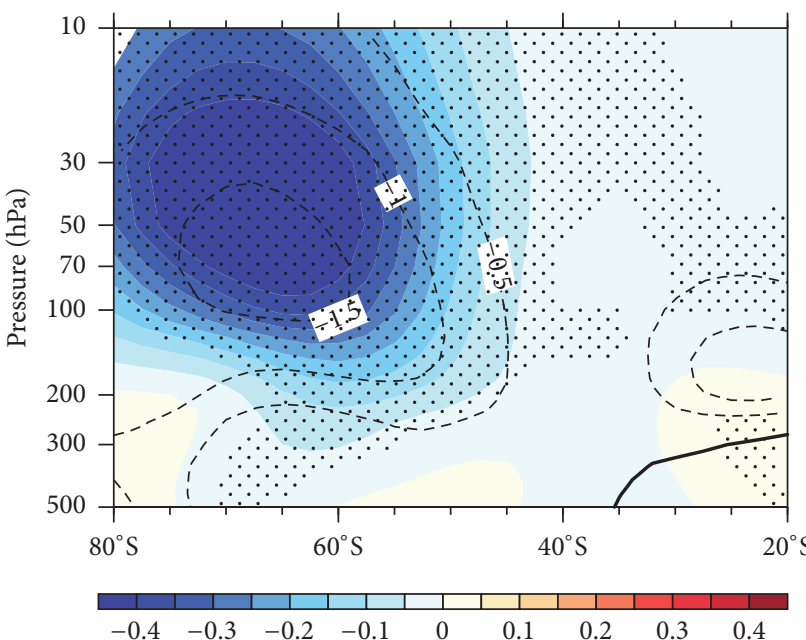

(a) $[1960-2000]$

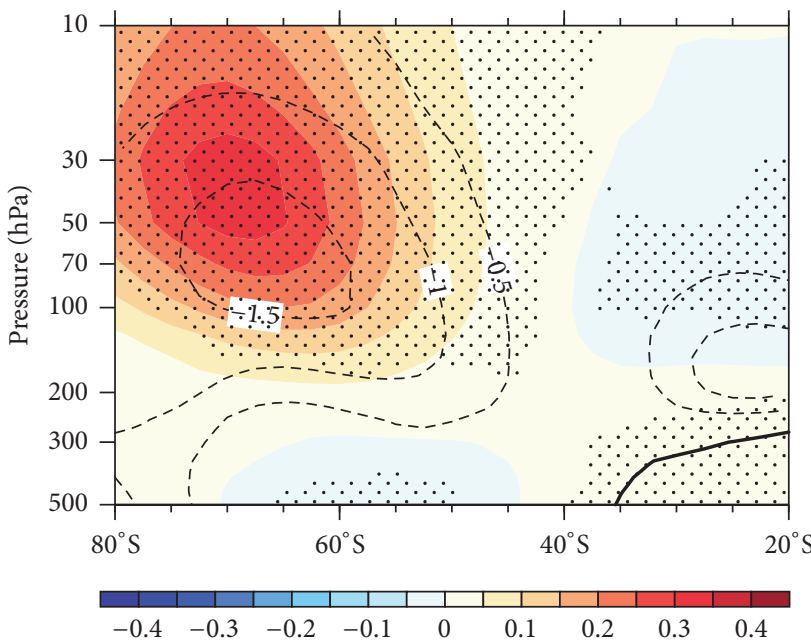

(c) $[2001-2050]$

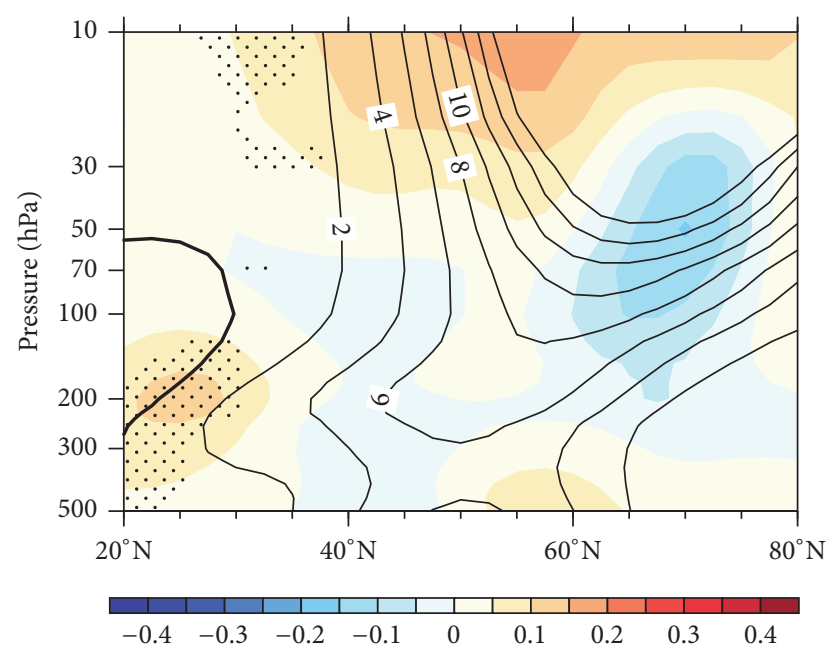

(b) $[1960-2000]$

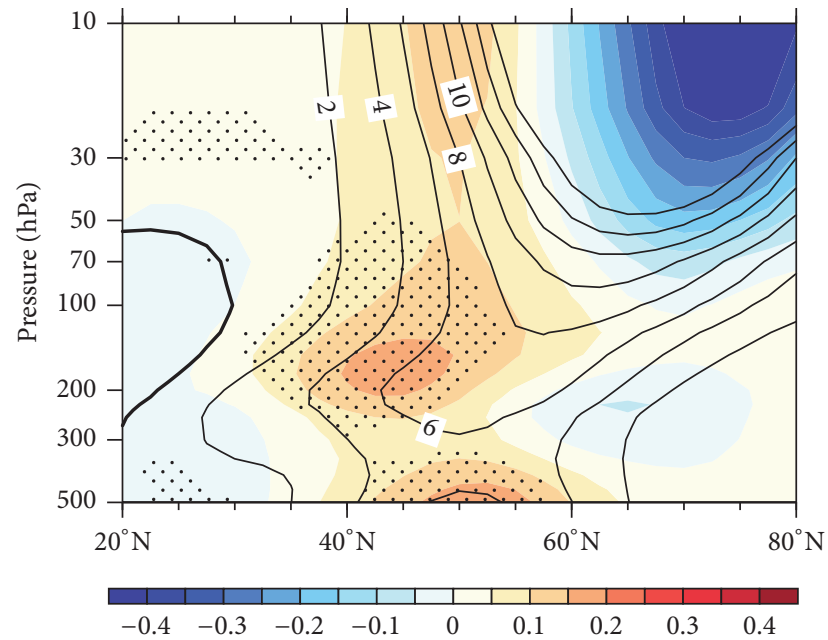

(d) [2001-2050]

Figure 7: Trends in the eddy heat flux (units: $\mathrm{K} \mathrm{m} \mathrm{s}^{-1}$ /decade) derived from the CCMs' ensemble mean in DJF over the periods (a, b) 1960-2000 and (c, d) 2001-2050, in the SH ((a) and (c)) and NH ((b) and (d)). The contour intervals for the climatological eddy heat flux in the $\mathrm{SH}$ and $\mathrm{NH}$ are $0.5 \mathrm{~K} \mathrm{~m} \mathrm{~s}^{-1}$ and $2 \mathrm{~K} \mathrm{~m} \mathrm{~s}^{-1}$, respectively. Solid and dashed lines represent positive and negative contours, respectively. Stippled regions show the trends significant at the $95 \%$ level.

ozone depletion than in response to elevated GHGs. The responses of westerly winds over the Antarctic stratosphere to stratospheric ozone depletion (Figure 9(b)) are stronger than those to the increase in GHGs (Figure 9(d)), via the thermal wind balance. Stratospheric ozone depletion and elevated GHGs both cause a decrease in temperature in the Arctic stratosphere (Figures 9(b) and 9(d)), consistent with the cooling trends in the Arctic stratosphere during the two periods shown in Figure 6. The responses of temperature and zonal winds in the two hemispheres to stratospheric ozone depletion and elevated GHGs are in accordance with the responses of the BDC in the two hemispheres shown in Figure 8 . The influences of stratospheric ozone depletion and the increase in GHGs on the temperature and zonal winds in the polar stratosphere may affect the planetary-wave propagation; that is, more planetary waves caused by the stratospheric ozone depletion (elevated GHGs) propagate into the Antarctic (Arctic) stratosphere (figure not shown), further modifying the BDC.

Recall that, during boreal winter, the southern downward mass flux strengthens over 1960-2000 and weakens over 2001-2050, while the northern downward mass flux strengthens during both periods. Because the stratospheric ozone changes have a more important role in the southern downward mass flux $[2,10]$ and the potential ozone recovery in the future climate $[47,48]$ will result in a weaker BDC [10], it is suggested that the smaller rate of the acceleration with respect to southern downward mass flux trend during 2001-2050 compared with 1960-2000 is closely related to the stratospheric recovery, which is expected to reach pre1980 levels by around 2050 [26]. As the ozone depletion in the Arctic stratosphere is less significant than that in 


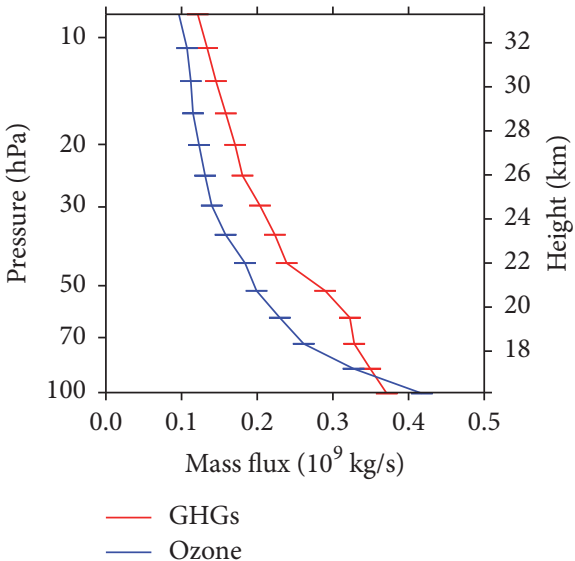

(a) Tropical upwelling

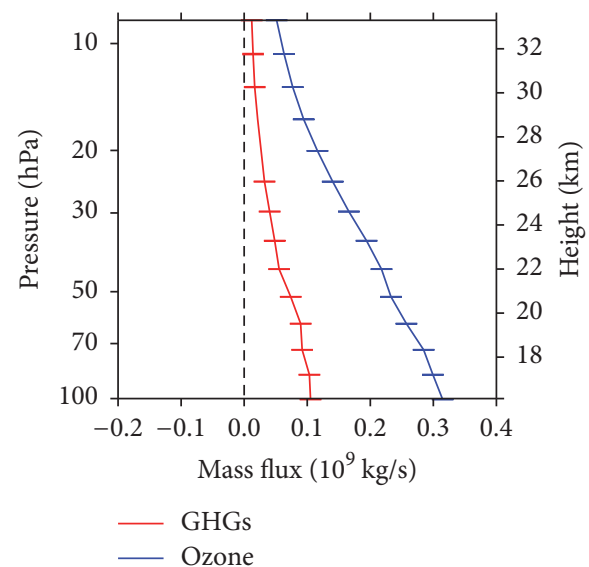

(b) SH downwelling

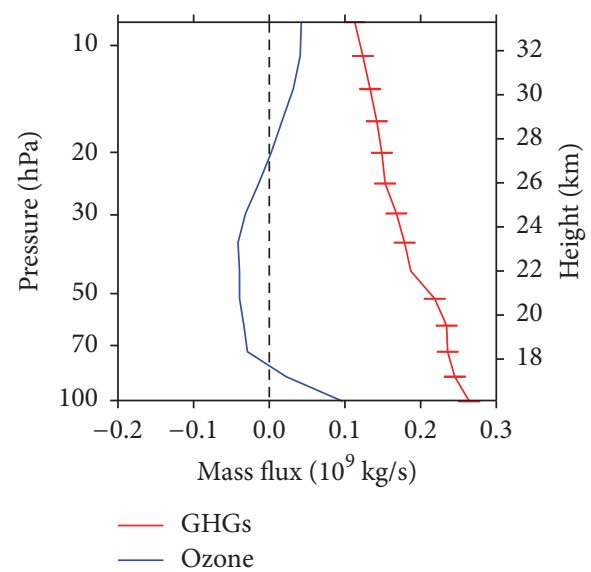

(c) NH downwelling

Figure 8: Vertical distributions of the differences in the (a) tropical upward mass flux, (b) southern downward mass flux, and (c) northern downward mass flux between runs OZONE2000 and REF (blue lines) and GHG2000 and REF (red lines) in DJF. The bars indicate that the differences are statistically significant at the $95 \%$ level.

TABle 3: The DJF mass flux (units: $10^{9} \mathrm{~kg} \mathrm{~s}^{-1}$ ) at $72 \mathrm{hPa}$ in the different experiments. Positive and negative values denote upward and downward mass flux, respectively. Percentage changes of the mass flux (in parentheses) caused by ozone or GHGs changes in the different experiments are estimated relative to that of the control run, REF.

\begin{tabular}{lccc}
\hline Experiments & $\begin{array}{c}\mathrm{SH} \\
\text { downwelling }\end{array}$ & $\begin{array}{c}\text { Tropical } \\
\text { upwelling }\end{array}$ & $\begin{array}{c}\text { NH } \\
\text { downwelling }\end{array}$ \\
\hline REF & -1.62 & +8.68 & -7.10 \\
OZONE2000 & $-1.88(+16.0 \%)$ & +8.91 & -7.07 \\
& & $(+2.6 \%)$ & $(-0.4 \%)$ \\
GHG2000 & $-1.71(+5.5 \%)$ & +9.04 & -7.38 \\
& & $(+4.1 \%)$ & $(+3.9 \%)$ \\
\hline
\end{tabular}

the Antarctic stratosphere, the influences of increased concentrations of GHGs on the northern downwelling are much more significant than those of the stratospheric ozone changes.

\section{Conclusions and Discussion}

Using a series of long-term integrations of stratosphereresolving coupled CCMs, the trends of the BDC during the second half of the 20th century (1960-2000) and first half of the 21st century (2001-2050) are examined. Three time-slice simulations are also designed and run in a state-of-the-art CCM (WACCM) to explore the effects of stratospheric ozone depletion and elevated GHGs on the BDC. The ensemble mean of the CCMs shows the BDC to have a strengthening trend during both the historical (1960-2000) and future (2001-2050) periods; however, the acceleration rates of the tropical upward branch and southern downward branch of the $\mathrm{BDC}$ in the latter period are smaller than those in the former (although the acceleration rate of the northern downward branch of the BDC in the future period is slightly larger than that in the historical period). This result suggests that, under the expected climate of the future, northern downwelling may play a more important role in balancing tropical upwelling. 


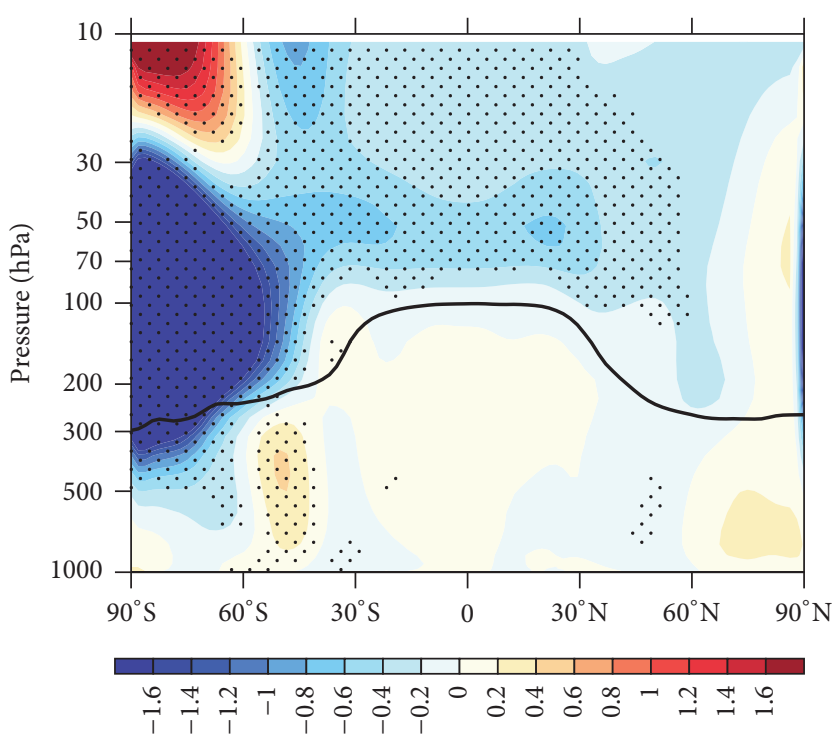

(a) $T$ [OZONE2000-REF]

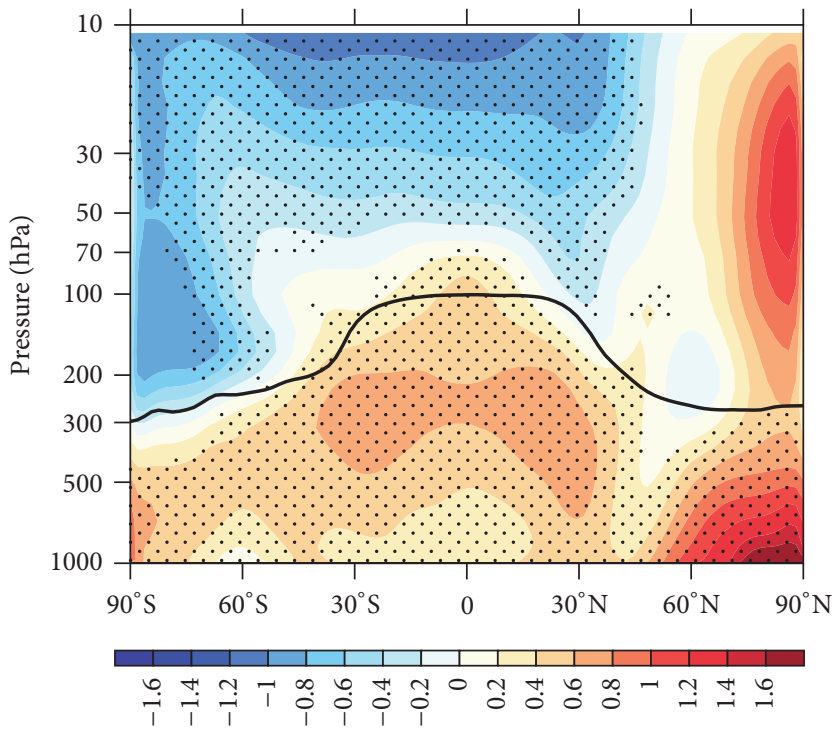

(c) $T$ [GHG2000-REF]

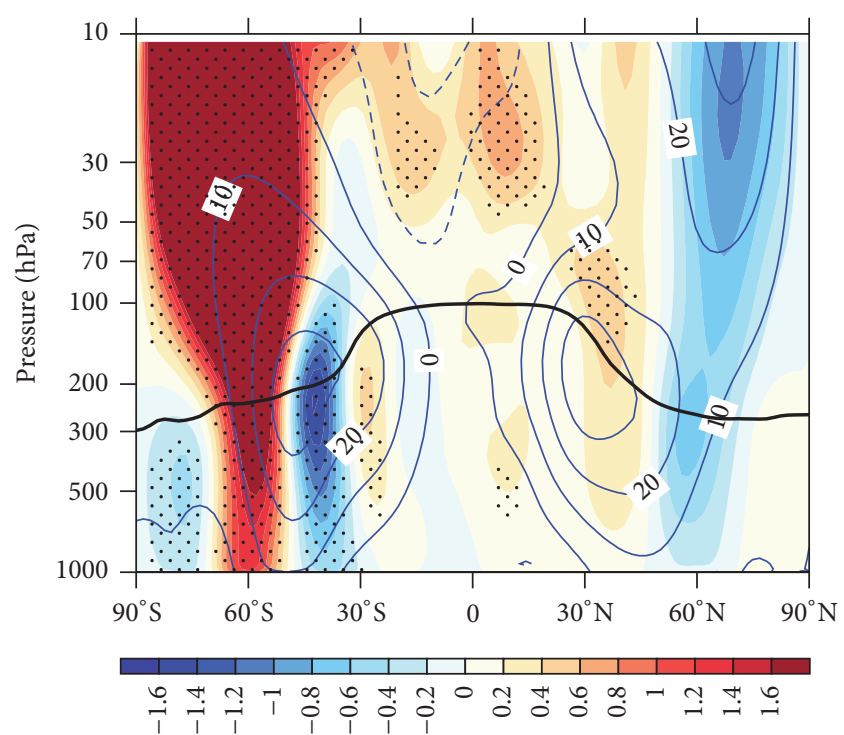

(b) $U$ [OZONE2000-REF]

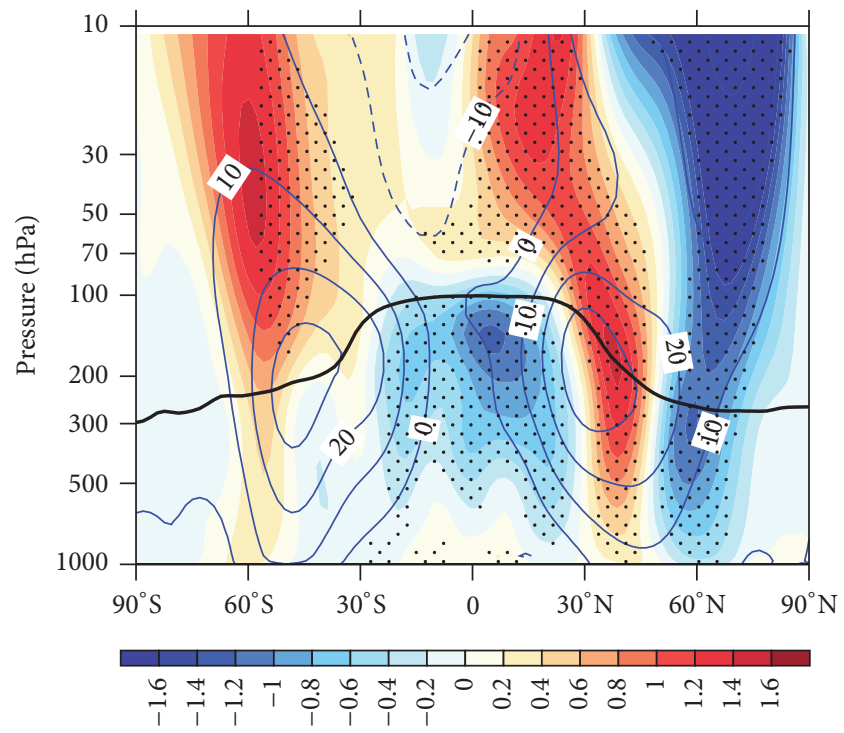

(d) $U$ [GHG2000-REF]

FiguRE 9: As in Figure 6, but for the differences in zonal mean ((a), (c)) temperature and ((b), (d)) zonal winds in DJF between runs ((a), (b)) OZONE2000 and REF and ((c), (d)) GHG2000 and REF. The thick black lines represent the climatological positions of the thermal tropopause in the REF run.

The differences between the trends of extratropical downwelling during the two periods are closely related to different changes in planetary-wave propagation from the troposphere into the polar stratosphere. During 1960-2000, a colder polar stratosphere and warmer troposphere enhance the latitudinal temperature gradient, further altering the westerly wind in the polar stratosphere, via the thermal wind relationship. Hence, more planetary waves propagate into the stratosphere during 1960-2000, resulting in a strengthened BDC. However, during 2001-2050, a warmed Antarctic stratosphere weakens the latitudinal temperature gradient and the Antarctic westerly wind, further shifting the southern subtropical jet equatorward, which leads to fewer planetary waves propagating into the Antarctic stratosphere and a weakening of the southern branch of the BDC. The strengthened subtropical jet in the $\mathrm{NH}$ during both periods is accompanied by more planetary waves propagating into the stratosphere at midlatitudes. The slightly larger acceleration rate of the northern downward branch of the BDC over 2001-2050 compared to that over 1960-2000 is possibly related to the larger number of planetary waves propagating into the stratosphere at midlatitudes during 2001-2050.

The time-slice experiments conducted using WACCM imply that the southern downwelling in response to the 
stratospheric ozone depletion is larger than that in response to elevated concentrations of GHGs, but that the latter plays a more important role in the northern downwelling. Coupled CCM simulations have shown that the stratospheric ozone may recover to pre-1980 levels by around 2050 [26]. Furthermore, the recovery of stratospheric ozone may cause an almost opposite effect on the BDC in the $\mathrm{SH}$ to that caused by stratospheric ozone depletion; that is, the recovery of stratospheric ozone will result in a weaker BDC [10]. This suggests that the smaller acceleration rate of the southern downwelling trend over 2001-2050 in comparison with that over 1960-2000 is closely related to the recovery of stratospheric ozone. Because the effects of the potential recovery of stratospheric ozone are opposite to those resulting from an increase in concentrations of GHGs, in the future, changes in the stratospheric atmosphere may feature a turning point under the conditions of the potential ozone recovery and GHG changes. However, when and where this turning point will be first reached remain unknown.

\section{Conflicts of Interest}

The authors declare that there are no conflicts of interest regarding the publication of this paper.

\section{Acknowledgments}

The authors are grateful to the groups and agencies for providing the datasets used in this study. This work was jointly supported by the Natural Science Foundation of Jiangsu Province of China (BK20160949), National Natural Science Foundation of China (41330425, 41675039, and 91537213), and the Postdoctoral Science Foundation of China (2016M591882) and PAPD project of Jiangsu Province.

\section{References}

[1] J. R. Holton, P. H. Haynes, M. E. McIntyre, A. R. Douglass, R. B. Rood, and L. Pfister, "Stratosphere-troposphere exchange," Reviews of Geophysics, vol. 33, no. 4, pp. 403-439, 1995.

[2] F. Xie, W. Tian, and M. P. Chipperfield, "Radiative effect of ozone change on stratosphere-troposphere exchange," Journal of Geophysical Research Atmospheres, vol. 114, no. 7, Article ID D00B09, 2009.

[3] J. Shu, W. Tian, J. Austin, M. P. Chipperfield, F. Xie, and W. Wang, "Effects of sea surface temperature and greenhouse gas changes on the transport between the stratosphere and troposphere," Journal of Geophysical Research Atmospheres, vol. 116, no. 2, Article ID D02124, 2011.

[4] C. Kobayashi and T. Iwasaki, "Brewer-Dobson circulation diagnosed from JRA-55," Journal of Geophysical Research: Atmospheres, vol. 121, no. 4, pp. 1493-1510, 2016.

[5] D. Hu, W. Tian, F. Xie, J. Shu, and S. Dhomse, "Effects of meridional sea surface temperature changes on stratospheric temperature and circulation," Advances in Atmospheric Sciences, vol. 31, no. 4, pp. 888-900, 2014.

[6] Y. Yu, R. Ren, J. Hu, and G. Wu, "A mass budget analysis on the interannual variability of the polar surface pressure in the winter season," Journal of the Atmospheric Sciences, vol. 71, no. 9, pp. 3539-3553, 2014.
[7] J. Luo, W. Tian, Z. Pu et al., "Characteristics of stratospheretroposphere exchange during the Meiyu season," Journal of Geophysical Research Atmospheres, vol. 118, no. 4, pp. 20582072, 2013.

[8] S. Solomon, "Stratospheric ozone depletion: A review of concepts and history," Reviews of Geophysics, vol. 37, no. 3, pp. 275316, 1999.

[9] C. H. Shi, B. Zheng, Y. J. Chen et al., "The quasi-biennial oscillation of water vapor in tropic stratosphere," Chinese Journal of Geophysics, vol. 52, no. 10, pp. 2428-2435, 2009.

[10] D. Hu, W. Tian, F. Xie, C. Wang, and J. Zhang, "Impacts of stratospheric ozone depletion and recovery on wave propagation in the boreal winter stratosphere," Journal of Geophysical Research: Atmospheres, vol. 120, no. 16, pp. 8299-8317, 2015.

[11] W. Wang, W. Tian, S. Dhomse, F. Xie, and J. Shu, "Stratospheric ozone depletion from future nitrous oxide increases," Atmospheric Chemistry Physics, vol. 13, no. 11, pp. 29447-29481, 2014.

[12] C. Shi, D. Guo, J. Xu, A. M. Powell Jr., and T. Xu, "The latitudinal structure of recent changes in the boreal BrewerDobson circulation," Atmospheric Chemistry \& Physics Discuss, vol. 15, no. 17, pp. 24403-24417, 2015.

[13] D. Hu, Y. Han, W. Sang, and F. Xie, "Trends of lower- and mid-stratospheric water vapor in chemistry-climate models," Atmospheric and Oceanic Science Letters, vol. 8, no. 1, pp. 57-62, 2015.

[14] A. Ossó, Y. Sola, K. Rosenlof, B. Hassler, J. Bech, and J. Lorente, "How robust are trends in the Brewer-Dobson circulation derived from observed stratospheric temperatures?" Journal of Climate, vol. 28, no. 8, pp. 3024-3040, 2015.

[15] C. I. Garfinkel, V. Aquila, D. W. Waugh, and L. D. Oman, "Time varying changes in the simulated structure of the Brewer Dobson circulation," Atmospheric Chemistry \& Physics, vol. 17, pp. 1313-1327, 2016.

[16] K. Minschwaner, H. Su, and J. H. Jiang, "The upward branch of the Brewer-Dobson circulation quantified by tropical stratospheric water vapor and carbon monoxide measurements from the Aura Microwave Limb Sounder," Journal of Geophysical Research: Atmospheres, vol. 121, no. 6, pp. 2790-2804, 2016.

[17] D. Rind, R. Suozzo, N. K. Balachandran, and M. J. Prather, "Climate change and the middle atmosphere. Part I: the doubled CO2 climate," Journal of the Atmospheric Sciences, vol. 47, no. 4, pp. 475-494, 1990.

[18] N. P. Gillett, M. R. Allen, and K. D. Williams, "Modelling the atmospheric response to doubled $\mathrm{CO} 2$ and depleted stratospheric ozone using a stratosphere-resolving coupled GCM," Quarterly Journal of the Royal Meteorological Society, vol. 129, no. 589, pp. 947-966, 2003.

[19] N. Butchart, A. A. Scaife, M. Bourqui et al., "Simulations of anthropogenic change in the strength of the Brewer-Dobson circulation," Climate Dynamics, vol. 27, no. 7-8, pp. 727-741, 2006.

[20] R. R. Garcia and W. J. Randel, "Acceleration of the brewerdobson circulation due to increases in greenhouse gases," Journal of the Atmospheric Sciences, vol. 65, no. 8, pp. 2731-2739, 2008.

[21] A. Engel, T. Möbius, H. Bönisch et al., "Age of stratospheric air unchanged within uncertainties over the past 30 years," Nature Geoscience, vol. 2, no. 1, pp. 28-31, 2009.

[22] D. Waugh, "The age of stratospheric air," Nature Geoscience, vol. 2, no. 1, pp. 14-16, 2009. 
[23] R. R. Garcia, W. J. Randel, and D. E. Kinnison, "On the determination of age of air trends from atmospheric trace species," Journal of the Atmospheric Sciences, vol. 68, no. 1, pp. 139-154, 2011.

[24] W. G. Wang, F. Y. Yang, H. Y. Wang et al., "The distribution characters of the stratospheric Brewer-Dobson circulation inferred from ERA-Interim," Chinese Journal of Geophysics, vol. 58, pp. 371-382, 2015.

[25] E. Manzini, B. Steil, C. Brühl, M. A. Giorgetta, and K. Krüger, “A new interactive chemistry-climate model: 2 . Sensitivity of the middle atmosphere to ozone depletion and increase in greenhouse gases and implications for recent stratospheric cooling," Journal of Geophysical Research D: Atmospheres, vol. 108, no. 14, 2003.

[26] E. C. Weatherhead and S. B. Andersen, "The search for signs of recovery of the ozone layer," Nature, vol. 441, no. 1, pp. 39-45, 2006.

[27] M. P. Chipperfield, S. S. Dhomse, W. Feng, R. L. McKenzie, G. J. M. Velders, and J. A. Pyle, "Quantifying the ozone and ultraviolet benefits already achieved by the montreal protocol," Nature Communications, vol. 6, article 7233, 2015.

[28] O. Morgenstern, M. A. Giorgetta, K. Shibata et al., "Review of formulation of present-generation stratospheric chemistryclimate models and associated external forcings," Journal of Geophysical Research Atmosphere, vol. 115, Article ID D00M02, 2010.

[29] V. Eyring, N. Butchart, D. W. Waugh et al., "Assessment of temperature, trace species, and ozone in chemistry climate model simulations of the recent past," Journal of Geophysical Research Atmosphere, vol. 111, Article ID D22308, 2006.

[30] J. R. Holton, "On the global exchange of mass between the stratosphere and troposphere," Journal of the Atmospheric Sciences, vol. 47, no. 3, pp. 392-395, 1990.

[31] J. Austin, D. Shindell, S. R. Beagley et al., "Uncertainties and assessments of chemistry-climate models of the stratosphere," Atmospheric Chemistry \& Physics, vol. 3, pp. 1-27, 2003.

[32] H. J. Edmon, B. J. Hoskins, and M. E. McIntyre, "Eliassen-Palm cross sections for the troposphere," Journal of the Atmospheric Sciences, vol. 37, no. 12, pp. 2600-2616, 1980.

[33] SPARC CCMVal, "SPARC Report on the Evaluation of Chemistry-Climate Models, SPARC Rep. 5," in The SPARC Technical Papers, V. Eyring, T. G. Shepherd, and D. W. Waugh, Eds., University of Toronto, Toronto, Ontario, Canada, 2010, WCRP-132,WMO/TD-No. 152.

[34] R. R. Garcia, D. R. Marsh, D. E. Kinnison, B. A. Boville, and F. Sassi, "Simulation of secular trends in the middle atmosphere, 1950-2003," Journal of Geophysical Research Atmospheres, vol. 112, no. 9, Article ID D09301, 2007.

[35] Intergovernmental Panel on Climate Change, The Physical Science Basis. Contribution of Working Group I to the Fourth Assessment Report of the Intergovernmental Panel on Climate Change, Cambridge University Press, New York, NY, USA, 2007.

[36] J. R. Albers and T. R. Nathan, "Ozone loss and recovery and the preconditioning of upward-propagating planetary wave activity," Journal of the Atmospheric Sciences, vol. 70, no. 12, pp. 3977-3994, 2013.

[37] Z. Guan, Q. Zhang, and M. Li, "Interannual variations in atmospheric mass over liquid water oceans, continents, and seaice-covered arctic regions and their possible impacts on the boreal winter climate," Journal of Geophysical Research: Atmospheres, vol. 120, no. 23, pp. 11,846-11,861, 2015.
[38] C. Lu, Z. Guan, S. Mei, and Y. Qin, "The seasonal cycle of interhemispheric oscillations in mass field of the global atmosphere," Chinese Science Bulletin, vol. 53, no. 20, pp. 3226-3234, 2008.

[39] C. Hu, Z. Guan, and M. Li, "The seasonal cycle of redistribution of atmospheric mass between continent and ocean in the Northern Hemisphere," Science China Earth Sciences, vol. 57, no. 7, pp. 1501-1512, 2014.

[40] F. Li, J. Austin, and J. Wilson, "The strength of the BrewerDobson circulation in a changing climate: Coupled chemistryclimate model simulations," Journal of Climate, vol. 21, no. 1, pp. 40-57, 2008.

[41] Y. Hu, Y.Xia, and Q. Fu, "Tropospheric temperature response to stratospheric ozone recovery in the 21st century," Atmospheric Chemistry and Physics, vol. 11, no. 15, pp. 7687-7699, 2011.

[42] S. W. Son, E. P. Gerber, J. Perlwitz et al., "Impact of stratospheric ozone on Southern Hemisphere circulation change: a multimodel assessment," Journal of Geophysical Research Atmosphere, vol. 115, pp. 1-18, 2010.

[43] T. G. Shepherd and C. McLandress, "A robust mechanism for strengthening of the Brewer-Dobson circulation in response to climate change: Critical-layer control of subtropical wave breaking," Journal of the Atmospheric Sciences, vol. 68, no. 4, pp. 784-797, 2011.

[44] M. Weber, S. Dhomse, F. Wittrock, A. Richter, B.-M. Sinnhuber, and J. P. Burrows, "Dynamical control of $\mathrm{NH}$ and $\mathrm{SH}$ winter/spring total ozone from GOME observations in 1995-2002," Geophysical Research Letters, vol. 30, no. 11, pp. 37-1, 2003.

[45] L. Oman, D. W. Waugh, S. Pawson, R. S. Stolarski, and P. A. Newman, "On the influence of anthropogenic forcings on changes in the stratospheric mean age," Journal of Geophysical Research Atmospheres, vol. 114, no. 3, Article ID D03105, 2009.

[46] E. M. Bednarz, A. C. Maycock, and N. L. Abranam, "Future Arctic ozone recovery: the importance of chemistry and dynamics," Atmospheric Chemistry Physics, vol. 16, pp. 12159-12176, 2016.

[47] S. Solomon, D. J. Ivy, D. Kinnison, M. J. Mills, R. R. Neely, and A. Schmidt, "Emergence of healing in the Antarctic ozone layer," Science, vol. 353, no. 6296, pp. 269-274, 2016.

[48] J. Kuttippurath and P. J. Nair, "The signs of Antarctic ozone hole recovery," Scientific Reports, vol. 7, no. 1, 2017. 

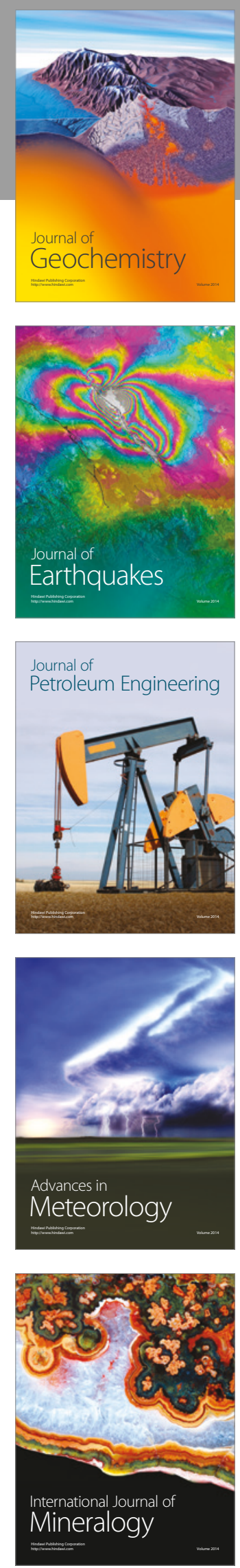
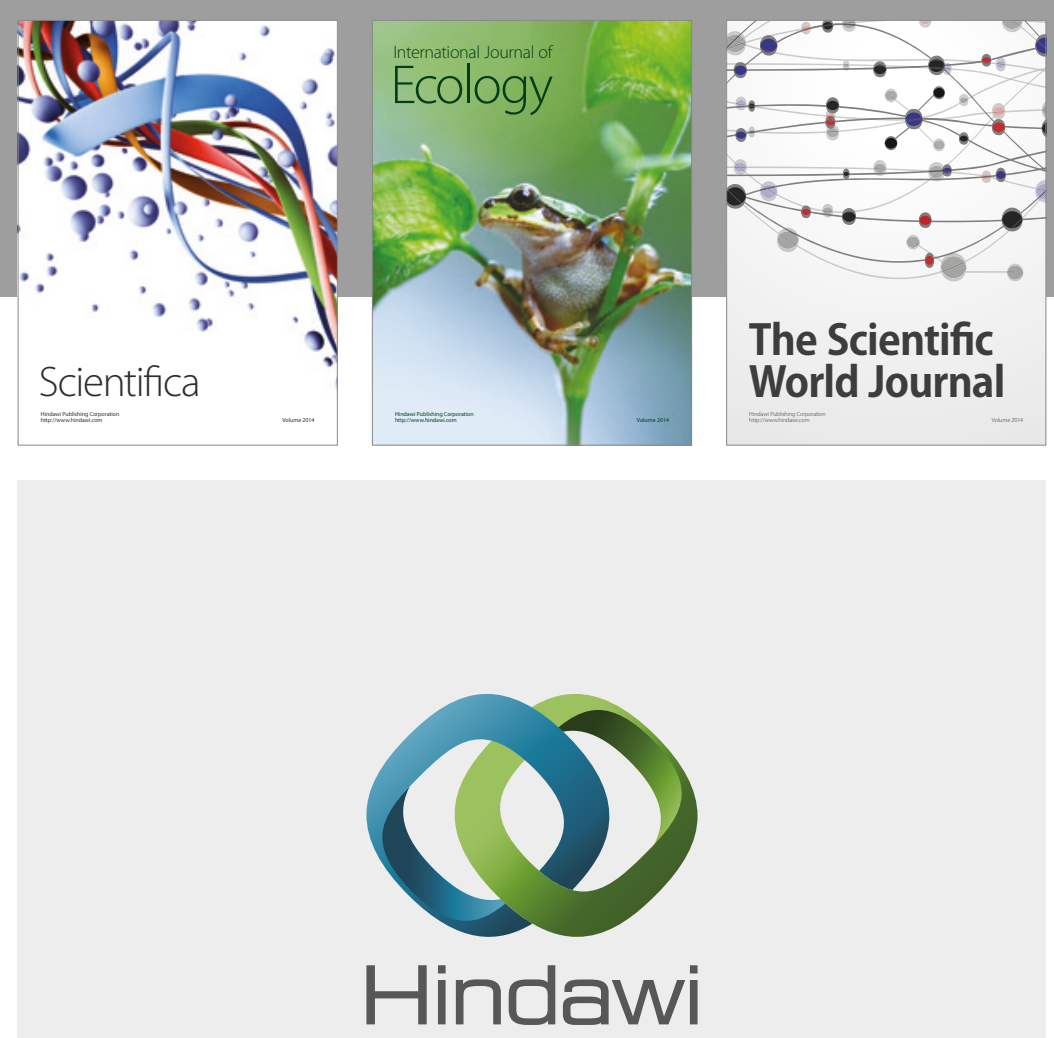

Submit your manuscripts at

https://www.hindawi.com
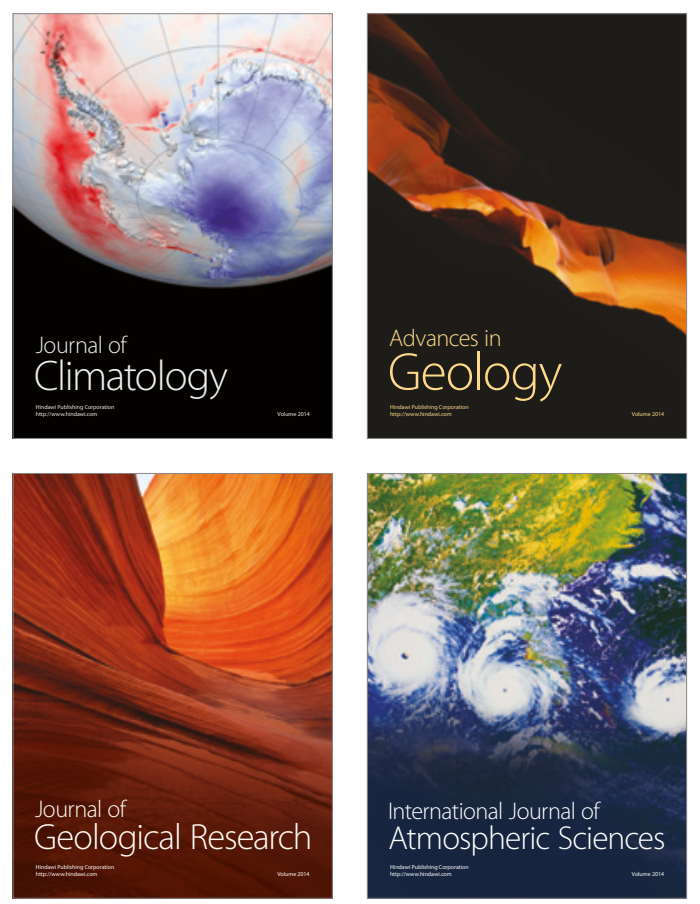

The Scientific

World Journal
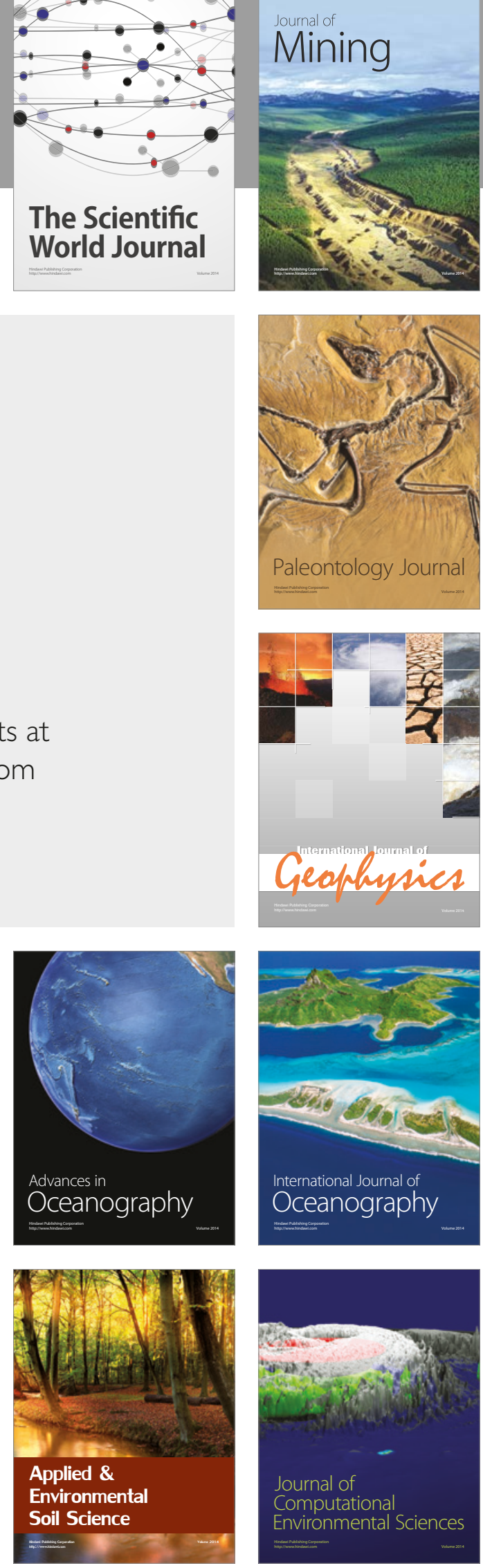